\title{
FEASIBILITY AND ECONOMIC EVALUATION OF LOW-COST EVAPORATIVE COOLING SYSTEM IN FRUIT AND VEGETABLES STORAGE
}

Tilahun $\mathrm{SW} *^{1}$

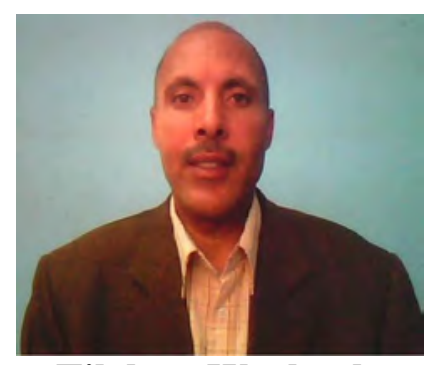

Tilahun W orkneh

*Corresponding author email: Tilahun Seyoum@yahoo.com

${ }^{1}$ School of Bioresource Engineering and Environmental Hydrology, Faculty of Engineering, University of Kwa-Zulu Natal, Private Bag X01, Scottsville, 3209, Pietermaritzburg, South Africa. 


\section{ABSTRACT}

The climate of most zones of Ethiopia is characterized as high ambient temperature combined with low relative humidity, which has a negative effect on fruit and vegetables quality during harvesting, transportation, storage and marketing. Low-cost natural and forced ventilation evaporative coolers have been developed for fresh fruit and vegetables storage under arid and semi-arid conditions. The coolers were found to be effective in maintaining micro-environmental conditions for fresh fruit and vegetables storage. This research was aimed at investigating the feasibility and economics of using forced ventilation low-cost evaporative cooling to improve the indoor air conditions such as temperature and relative humidity. To reduce the indoor temperature and raise relative humidity, low-cost forced air ventilation evaporative cooler of $2.6 \mathrm{~m}^{2}$ floor area was fabricated and tested at Haramaya University, Fruit and Vegetables Research Station, on the storability of banana, papaya, orange, mandarin, lemon, mango, tomato and carrot. A fixed operating air flow rate of $4.3 \mathrm{~kg}^{-}$ ${ }^{1}$ was used to evaluate cooling performance and energy efficiency ratio of the cooler. The results showed that the indoor dry bulb temperature significantly $(\mathrm{P}<0.001)$ drops parallel with a significant $(\mathrm{P}<0.001)$ rise in relative humidity during storage. The energy efficiency ratio (varying from 55 to 84\%) was found to be high as the evaporative cooling system requires small electric power only for operating fan and water pump. The economic analysis indicates that the payback period of the evaporative cooling system is less than 1.2 years. The results clearly demonstrate that the forced ventilation evaporative cooling system should be recommended for use in developing countries in order to maintain better quality of produce. These results demonstrated the relevance of the use of this low-cost adiabatic cooling technology for shelflife extension of fruits and vegetables and thereby encourage organized women groups to involve in this perishable commodity handling and processing as a source of income.

K ey words: Cooling, Fruits, Vegetables, Feasibility, Storage 


\section{INTRODUCTION}

Fruit and vegetables production can improve farmers' living conditions. Horticultural production gives a higher net value return to farmers in developing countries compared to other crop farming [1]. The climatic and soil conditions in Ethiopia allow growing a wide range of fruits and vegetables. With the variety of altitudes and microclimates, and the long growing season and accessible irrigation sources in Ethiopia, anything can grow well $[2,3]$. The report $[2,3]$ showed that nearly every fruit and vegetable is already available locally, but sufficient for everybody. Among several reasons responsible for limited availability and poor postharvest fruits and vegetables management are lack of economic power to purchase and install the expensive package house equipment, mechanical refrigeration system, proper means of transportation and technical knowledge. Also, the predominantly organic character of the Ethiopian agriculture provides a potential advantage to its produce at international markets [4]. However, the perishable nature of fruits and vegetables needs effective postharvest handling systems, the main reason for high postharvest losses in the tropical regions of Africa. In Ethiopia postharvest loses of vegetables is estimated from $25-40 \%[2,5]$.

In principle, fresh commodities need proper postharvest management to reduce loss and maintain quality. However, at present there is no improvement over traditional postharvest handling methods of fruits and vegetables in Ethiopia, throughout the market channel. The peasants have no storage facilities at their disposal and the fruits and vegetables they harvest are usually exposed to high temperatures and low relative humidity until wholesaler or retailers collect them. The trade also does not operate any intermediate storage for carrying oversupply to obtain better prices $[6,7]$. No cooling facilities or packaging houses at any stage of product line from farm to consumer or exports market are currently available. As a result, nutritional loss and postharvest decay are found to be the serious issues [2]. Reduced temperature decreases physiological, biochemical, and microbiological activities, which are the causes of quality deterioration (flavour, texture, colour, and nutritive value).

Temperature of the surrounding air and produce can be reduced by forced air-cooling, hydro cooling, vacuum cooling, ice cooling, and adiabatic cooling [8]. However, these cooling methods, with the exception of adiabatic cooling, are expensive for smallscale peasant farmers, retailers, and wholesalers in Ethiopia, as they require high initial cost and electrical sources. In spite of that, however, it is essential to control storage temperature and relative humidity during storage as they are the main causes of fruit and vegetable deterioration during ripening and storage. As an alternative, introduction of simple and low cost psychrometric units at different stages starting from farm to the retail market should be the solution. Evaporative cooling systems are commonly used in countries where the climate is hot and dry, as found in most zones of Ethiopia. Several studies have been devoted to the application of evaporative cooling principles in the field of fruit and vegetables preservation mostly in India and the USA [8 - 13]. The potential energy savings envisaged by replacing conventional refrigerated systems by evaporative systems is $\sim 75 \%$ [14]. Evaporative cooling is an 
adiabatic cooling process whereby the air takes in moisture which is cooled while passing through a wet pad or across a wet surface showed that evaporative cooled storage is more energy efficient than a mechanical refrigeration system [8]. Under Ethiopian climatic conditions, relatively low temperature and high relative humidity were achieved by using less expensive methods of cooling such as evaporative cooling $[15,16]$. This paper presents an investigation on the feasibility and economics of using evaporative cooling in improving the shelf life of fruits and vegetables.

\section{ANALYSIS}

\section{Cooling Efficiency and Enthalpy Change in Air}

Analysis of the moist air properties is important to look at the suitability of a given modified air condition for fruit and vegetables storage in hot climate. Cooling efficiency $\eta$ is an index used to assess the performance of a direct evaporative cooler. Cooling efficiency in percentage can be defined as follows [17]:

$$
\eta=\frac{\mathrm{T}_{\mathrm{d}}-\mathrm{T}_{\mathrm{c}}}{\mathrm{T}_{\mathrm{d}}-\mathrm{T}_{\mathrm{w}}} \times 100
$$

where: $T_{d}$ and $T_{w}$ are the dry and wet bulb temperatures of the ambient air and $T_{c}$ is the dry bulb temperature of the cooled air in $1{ }^{\circ} \mathrm{C}$.

The enthalpy change in air $\Delta \mathrm{H}$ can be calculated as follows:

$$
\Delta H=M C_{p a}\left(T_{d}-T_{c}\right)
$$

where: $\mathrm{C}_{\mathrm{pa}}$ is the specific heat of moist air in $\mathrm{kJ} \mathrm{kg}^{-1} \mathrm{~K}^{-1}$; and $\mathrm{M}$ is the air mass flow rate in $\mathrm{kg} \mathrm{s}^{-1}$.

\section{Energy Efficiency Ratio}

Energy efficiency ratio (EER) was developed by the industry to evaluate the rate of energy consumption for air conditioning units [18]. The Energy efficiency ratio represents a measure for rating air conditioning units. The energy efficiency ratio is defined as the net thermal energy removed from air for cooling purposes per watt of energy expended. That is

$$
E_{E R}=\frac{\Delta H}{P}
$$

where $\Delta H$ is difference in the enthalpy of the inlet and outlet air streams through the cooling pad and $\mathrm{P}$ is input electrical power in $\mathrm{kW}$ of the exhaust fan and water pump. The value of $E_{E R}$ is calculated by determining the difference in the enthalpy of the inlet and outlet air streams through the cooling pad and the input power. 


\section{MATERIALS AND METHODS}

\section{Experimental Evaporative Cooler}

Figures 1 and 2 show a schematic diagram of the forced air evaporative cooler [15]. The inner dimensions of the unit were $2 \mathrm{~m} \times 2 \mathrm{~m} \times 1.3 \mathrm{~m}$, to hold a capacity of about $0.5 \mathrm{t}$ fruits. The frame was constructed from $25 \mathrm{~mm} \times 25 \mathrm{~mm} \times 4$ angle iron. The side and top surfaces of the cooler were covered by sheet metal (1-mm thickness). In order to obtain good strength, the sheet metal was properly welded, both along the vertical and horizontal angled iron pieces. The cooler consisted of three major units, viz., an air conditioning unit, a watering system, and a storage chamber. The water distribution system was designed so that water was continuously pumped to the top surface of the cooler and to the cooling pad. The top surface of the structure was designed to enable water to run down over the four surfaces by gravity and back into a holding tank. The water tank (A) was placed below ground level and a vertical water pipe was installed to withdraw water from the tank during operation (B). During operation, water was sprinkled by a small $0.20 \mathrm{KW}$ water pump (C) over the top surface, to wet the top surface and all four sides of cooling pad layers through, vertical water pipe (E), by a horizontal perforated pipe (F). The hose (D) was connected from a vertical pipe (E) to sprinkle water continuously on the cooling pad filled with charcoal $(\mathrm{H})$ into the evaporative cooling chamber, to effectively increase the relative humidity, while the temperature was decreased. The fan (G) derived air through the evaporative cooling pad. In Fig.1, the directions of the arrows show the airflow pattern after passing through the cooling pad $(\mathrm{H})$. To minimize bruising of produce and improve airflow, three equally spaced shelves $(\mathrm{J})$ were inserted. The dry bulb air temperature was monitored by thermocouples (Jenway-digital psychrometer 5105, U.K.) at the centre of the cooler (I). An air vent was inserted in the top of the cooler $(\mathrm{N})$. The three side surfaces and the door were covered with a thin layer pad of $5 \mathrm{~mm}$ jutie sack (M), which was sandwiched between sheet metal from inside $(\mathrm{K})$ and mesh wire (L) on the outside, facing the ambient air, to allow evaporation. In this way, the surface area from which evaporation of water can take place was maximized.

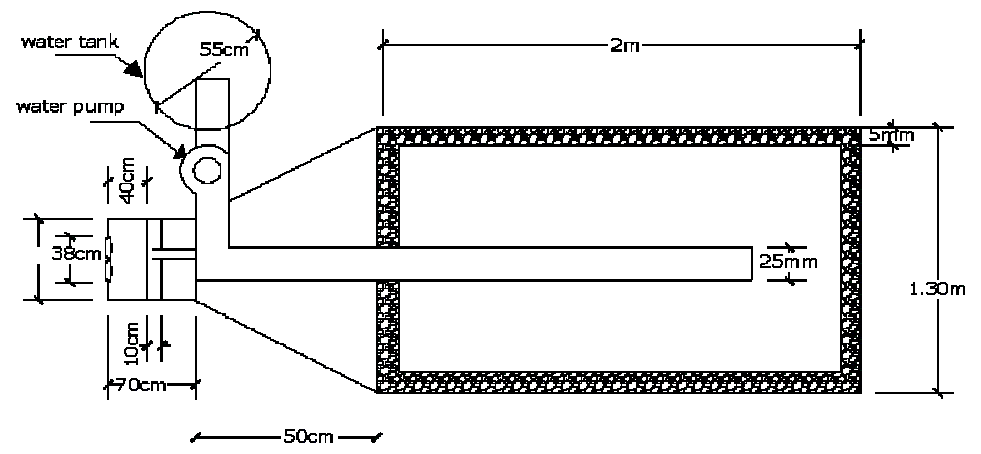

Figure 1: Plan view of the evaporative cooling unit 


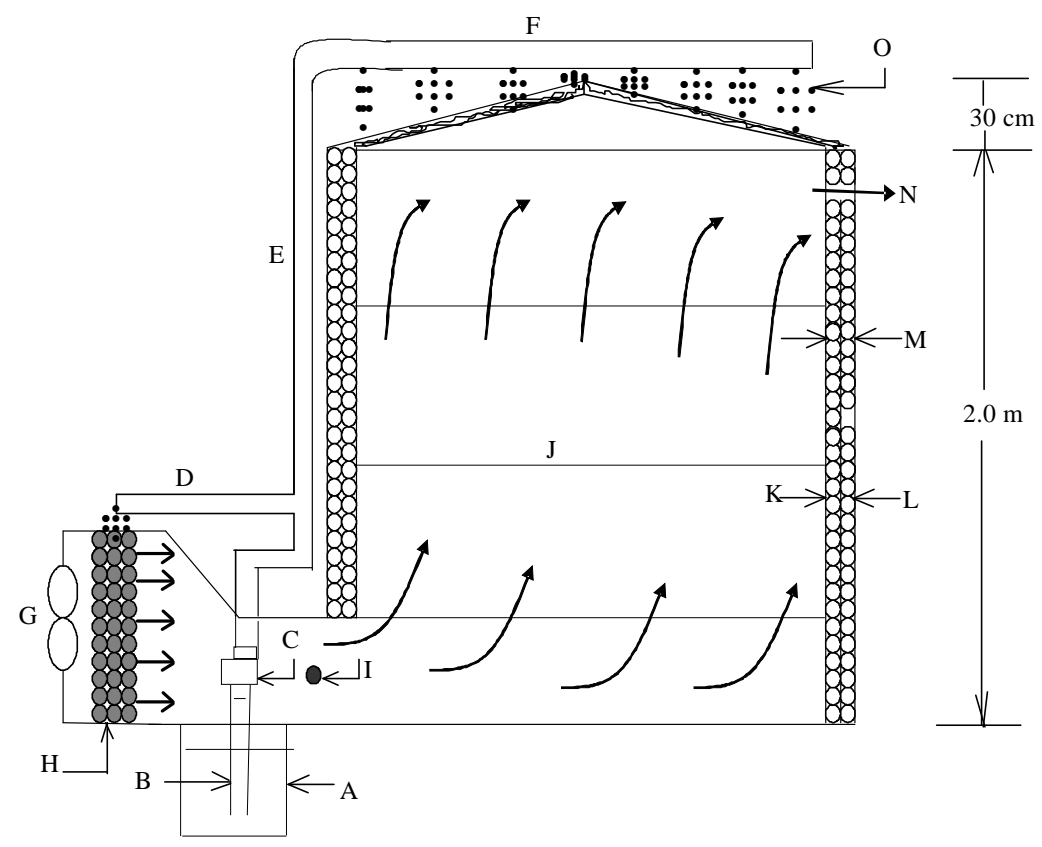

Figure 2: Schematic diagram of an experimental evaporative cooler: A, water tank; B, vertical pipe connected to water pump; C, water pump $(0.5$ hp); D, water hose to cooling pad; E, vertical water pipe; F, perforated horizontal water pipe; $\mathrm{G}$, fan; $\mathrm{H}$, cooling pad (charcoal); I, location of thermocouple and hygrometer; J , storage chamber; K, sheet metal; L, mesh wire; $M$, wet jetty sack layer; $N$, ventilation port; 0 , water

\section{Temperature and relative humidity measurement}

The air temperature and relative humidity were controlled throughout the 23 days period. Temperature and relative humidity were recorded using digital psychrometer units (Jenway-digital psychrometer 5105, U.K.) attached to thermocouples located in the evaporative cooler as indicated by letter I in Fig. 1 and outside of the evaporative cooler to record ambient temperature. The readings were made at 2-h intervals during the day-time period from $500 \mathrm{~h}$ to $1800 \mathrm{~h}$ for 23 days. The average indoor and ambient temperature and relative humidity were calculated from the 23 days data separately for each time. The power consumption of the fan and water pump was measured using power meter (Hioki model 3286, Japan).

\section{E conomic evaluation}

The fixed costs of the evaporative cooler remained constant for all the fruits and vegetables. The reason for this was that expenses associated with costs of materials used for construction and air conditioning equipments were the same. Workshop technologist and other labour costs during the construction period were also included in this cost component. There was no additional fixed cost for a specific fruit or 
vegetable. In the variable cost component all the variable expenses such as fruit and vegetable samples, maintenance, electricity, water and labour costs were included.

\section{RESULTS}

\section{Temperature and R elative H umidity Fluctuation}

Figure 3 shows the changes in the air temperature during forced air evaporative cooling. The evaporative cooling system significantly $(\mathrm{P}<0.001$, where $\mathrm{P}$ is the level of significance) reduced the air temperature. The data clearly showed that the evaporative cooling system maintained the average temperature approximately constant during the day time as shown in Figure 3. While the average ambient air temperature continuously increased during $500 \mathrm{~h}$ to $1200 \mathrm{~h}$ and decreased thereafter from $1200 \mathrm{~h}$ to $1800 \mathrm{~h}$. The evaporative cooled storage chamber air temperature decreased from 36 to $16.4^{\circ} \mathrm{C}$ while relative humidity increased from 25.4 to $91.1 \%$, which is appropriate for reducing postharvest losses of fruits and vegetables due to physiological weight loss [19]. Similarly, the data presented in Figure 4 clearly revealed that the evaporative cooling system maintained the relative humidity approximately constant when compared with the ambient relative humidity that was fluctuating during the experiment. The results in this study indicate that the evaporative cooling system significantly $(\mathrm{P}<0.001)$ increased the relative humidity of the air as shown in Figure 4, hence indicate possible reduction in physiological weight loss from fruit and vegetables [15].

The cooling efficiency is affected by several factors, such as pad design, thickness of pad, air flow rates and outside air temperature and relative humidity [20]. Using a fixed $10 \mathrm{~cm}$ thickness of pad, the cooling efficiency varies between $55 \%$ and $84 \%$. This result agreed well with that presented in Lertsatitthanakorn et al. and Watt [20, 21].

The power consumption in $\mathrm{kWh}$ for a fixed $4.3 \mathrm{kgs}^{-1}$ air mass flow rates were 1.13. The energy efficiency ratio was 26.3 at air mass flow rates of $4.3 \mathrm{~kg}^{-1}$. This is due to the evaporative cooling effect, which prevails over power consumption during the experiment. 


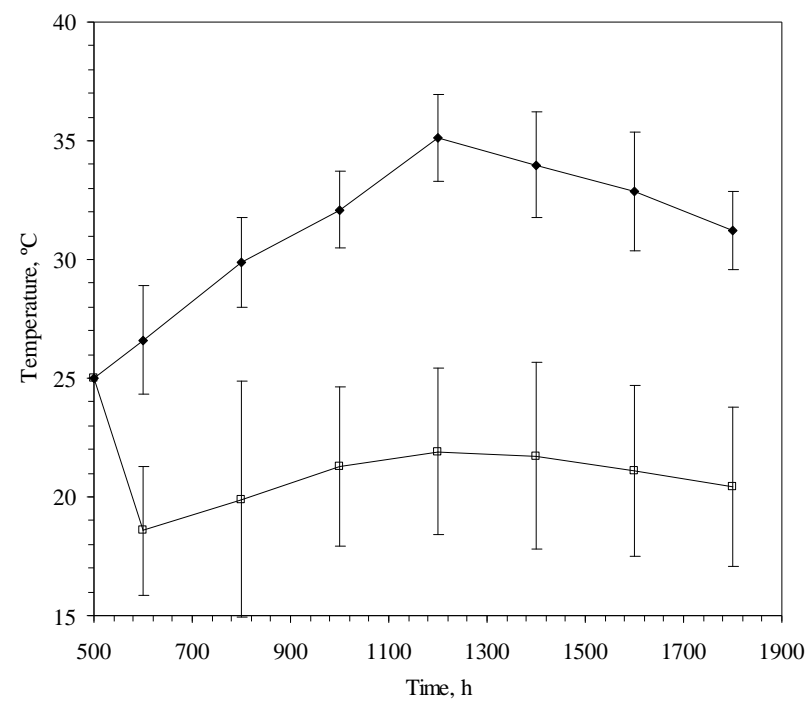

Figure 3: The effect of day time on dry-bulb average environmental and evaporative cooler temperature $\left({ }^{\circ} \mathrm{C}\right)$. Data are means of 23 replications; bars are standard deviation. $-\square$, cooler and $-\mathbf{\Lambda}-$-, ambient

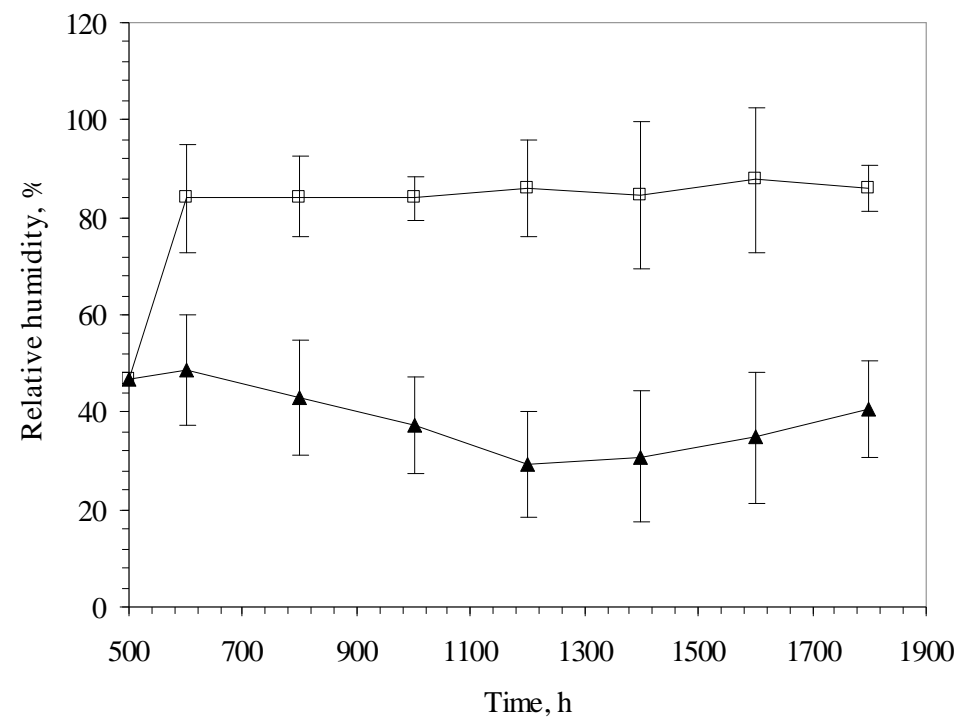

Figure 4: The effect of day time on the average environmental and evaporative cooler relative humidity (\%). Data are means of 23 replications; bars are standard deviation. $-\square$, cooler and $-\mathbf{\Lambda}-$, ambient

Fruit and vegetable storage-demonstrative application

The general question of feasibility of the evaporative cooler and its application in developing countries has not been addressed in the previous studies [15, 16, 19]. Experiments performed on the evaporative cooling system for storing several fruits and vegetables including banana, papaya, orange, mandarin, lemon, mango, tomato, carrot are used to illustrate a possible application. The evaporative cooled storage has shown to maintain the fruits and vegetables $100 \%$ marketable for at least 15 days [15, 16, 19]. Under hot climate conditions of Ethiopia, these perishable commodities will 
became unmarketable within 15 days period, while those stored in the evaporative cooled chamber remained $100 \%$ marketable even after two weeks of storage. The reason for this was attributed to the fact that the evaporative cooling system was capable of reducing the temperature and increasing the relative humidity as required for short period fruit and vegetable storage during marketing (Fig. 2 and 3). Consequentially, an alternative evaporative cooling system was proposed for application at farmer, retailer and wholesaler level along the market flow channel until the product reaches the consumer. Consequently, as the experiments revealed, the evaporative cooling system should be recommended.

\section{E conomic Evaluation}

In this section, a cost analysis of the evaporative cooling is evaluated. A payback period is employed to determine the period of time required for a project that could be attributed to using the evaporative cooled storage for fruit and vegetables retail or wholesale. The payback period is defined as the investment of time required for the project of an investment to equal the cost of the investment [22]. The 100\% marketable shelflife of banana, papaya, orange, mandarin, lemon, mango, tomato, carrot is 15 days or above. Assuming $500 \mathrm{~kg}$ of a given fruit or vegetable is sold within 15 days, while there is no risk of losses in the evaporative cooled storage, the total amount of a fruit or vegetable becomes $1000 \mathrm{~kg}$ per month. If a fruit or vegetable is continuously produced throughout the year the total quantity of a produce that a retailer can handle may reach $12000 \mathrm{~kg}$ per year. However, mango, papaya, mandarin and lemon are available only for 3 to 4 months in a year. Banana, tomato, carrot and orange are available 12 months or throughout the year. Thus, the economic computation is based on the number of months that each fruit or vegetable is available in market. Thus, assuming the percentage marketability of the produces was $100 \%$, the total quantity of mango, papaya, banana, tomato, carrot, orange, mandarin, lemon that can be handled using a 0.5 tonne evaporative cooled storage are 3000,4000 , $12000,12000,12000,12000,4000,4000 \mathrm{~kg}$ per year, respectively. During 2006, the purchase price of mango, papaya, banana, tomato, carrot, orange, mandarin, lemon in the local market from the producer by either retailer or wholesaler were at 1.50, 2.50, $2.50,1.75,0.80,2.75,2.75,3.00$ Birr per $\mathrm{kg}$, respectively. The retailer sells mango, papaya, banana, tomato, carrot, orange, mandarin, lemon in the local market at 4.00, 5.00, 3.50, 3.50, 2.00, 4.50, 4.00, 5.00 Birr per kg, respectively. The resulting annual income would have been varied with the produce as shown in Table 1. Fixed costs for the evaporative cooler, including those for construction cost, fan, pump, piping and cooling pad, were 438.82 USD. Variable costs, mainly the fruit or vegetable and other input, power cost would have been varied with the fruit and vegetable as shown in Table 1. These costs, summation of variable and fixed expenses, divided by the annual income give a payback period of approximately 1.0, 0.9, 0.9, 0.7, 0.8, 0.8, 1.1, 0.8 years for mango, papaya, banana, tomato, carrot, orange, mandarin and lemon respectively. The summary of economic evaluation is given in Table 1 . Therefore, the use of evaporative cooled system in fruit and vegetable storage should be promoted as an alternative technology for the household farmer, retailers, wholesalers and exporters of perishable produces. Additional cost savings could be recognized in larger scale operations. 


\section{DISCUSSION}

Ethiopia has high fruit and vegetable production potential $[3,4,23]$, although, the annual yield is limited partly due to the reluctance of farmers to involve on these perishable produces. The forced ventilation evaporative cooling system was designed such that the temperature could be significantly reduced below ambient temperature, while maintaining a relative humidity up to high. As a result, storage in this evaporative cooler increases shelf lives of most fruits and vegetables to more than two weeks, compared to less than one week shelf life when stored at ambient conditions. Thus, it is clear that these low-cost and appropriate storage facilities should be installed at different centres throughout the hot arid and semi-arid tropical regions in order to promote fruit and vegetables production on private, cooperative or public basis. Evaporative cooling would be used to solve the problem associated with cooling fruits and vegetables.

The evaporative cooling has several economic advantages when compared with mechanical compression refrigeration system [14], for application in developing countries like Ethiopia. The advantages of evaporative cooling over mechanical compression systems are mainly due to low initial investment, low installation and maintenance costs, and reduction in insulation requirement and can be used by micro and small scale enterprises dealing with fruit and vegetable marketing. In general, the cost of mechanical refrigeration system for fruits and vegetables storage by small to medium scale entrepreneurs is obviously very high and this adiabatic cooling technology could help to encourage the entrepreneurs.

\section{CONCLUSION}

The feasibility and economics of reducing the indoor temperature and raising the relative humidity of the evaporative cooled fruit and vegetables storage chamber by using direct evaporative cooling was investigated. An experimental forced ventilation evaporative cooler was built. The study was conducted in Dire Dawa, Ethiopia. It was found that the evaporative cooling system was capable of significantly $(\mathrm{P}<0.001)$ reducing the temperature and significantly $(\mathrm{P}<0.001)$ increasing the relative humidity as required for short time storage of selected fruits and vegetables such as carrot, mango, papaya, banana, mandarin, orange, lemon and tomato. Consequently, as the experiment indicated, the evaporative cooling system should be recommended for use by small scale farmers, retailers, wholesalers and exporters to nearby neighboring countries.

\section{ACK NOW LEDGMENTS}

The author would like to acknowledge the financial support and cooperation extended by Haramaya University and Ethiopian Agricultural Research Institute. The author would also like to thank the retailers, wholesalers and exporters in Dire Dawa and 
Harar towns, Ethiopia for their cooperation and assistance in obtaining data in this field. 


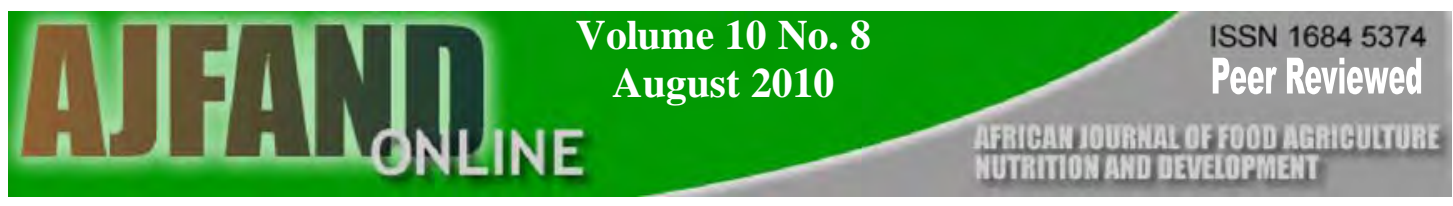

Table 1: Summary of economic evaluation of the evaporative cooling system

\begin{tabular}{|c|c|c|c|c|c|c|c|c|}
\hline \multirow{3}{*}{ Item } & \multicolumn{8}{|c|}{ Value, Birr } \\
\hline & \multicolumn{8}{|c|}{ Fruit and Vegetables } \\
\hline & Mango & Papaya & Banana & Tomato & Carrot & Orange & Mandarin & Lemon \\
\hline Fixed Cost & 5968 & 5968 & 5968 & 5968 & 5968 & 5968 & 5968 & 5968 \\
\hline Variable Cost & 5458 & 11279 & 33833 & 24832 & 13428 & 36835 & 11276 & 9280 \\
\hline Income & 12000 & 20000 & 42000 & 42000 & 24000 & 54000 & 16000 & 20000 \\
\hline
\end{tabular}




\section{REFERENCES}

1. Soerojo $R, W$ aliyah $L$ and $L W$ Chalidin The role of horticultural production on improvements of farmers' income. Acta Hort. 1991; 270: 103-110.

2. Agonafir Y Economics of horticultural production in Ethiopia. Acta H ort. 1991; 270: $15-19$.

3. US Department of Commerce Ethiopia: Fruits and vegtables exports growing. TradePort: International Market Insight (IMI), 07.12. (1999a). http://www.state.gov/r/pa/ei/bgn/2859.htm . Accessed on 12/08/2008.

4. US Department of Commerce Ethiopia: Trade mission boasts concrete results. TradePort: International Market Insight (IMI), 19.11. (1999b). http://www.state.gov/r/pa/ei/bgn/2859.htm. Accessed on 12/08/2008.

5. Food and Agricultural organization. Prevention of postharvest food losses: fruits, vegetables and root crops. Rome, 1989.

6. Hormann DM and $H$ Shawel The domestic market for fresh and processed fruits and vegetables and its supply in important urban centres of Ethiopia. Hannover and Addis Ababa, 1985.

7. Wolde B Horticulture marketing systems in Ethiopia. Acta Hort. 1991; 270: 21-31.

8. Thompson J F and RF K asmire The concept of evaporative cooling, American Vegetable Grower. 1981; 26: 43-46.

9. Rama MV, Krishnamurthy $\mathrm{H}$ and $\mathrm{P}$ Narasimham Evaporative cooling storage of potatoes in two model storage structures. J. Food. Sci. and Technol. Mysore 1990; 27(1): 19-21.

10. Rama $\mathrm{MV}$ and $\mathrm{P}$ Narasimham Evaporation cooling of potatoes in small naturally ventilated chambers. J. Food. Sci. and Technol. 1991; 28(3): 145-148.

11. Roy SK and RK Pal A low-cost cool chamber: an alternative technology for developing countries. In: Postharvest Handling of Tropical Fruits, ACIAR P roC. 1994; 50: 393-395.

12. Christenbury GD, Rushing JW and $M$ M ejia Field experiences with vegetable cooling devices for small farmers. American Society of Agricultural Engineers (ASAE); St Joseph; 29634, USA. Proceedings of a conference held in Guanajuato M exico, 1995. 
13. Thompson J F, M itchell FG, Runsey TR, Kasmire RF and $\mathrm{CH}$ Crisosto Commercial cooling of fruits, vegetables, and flowers. UC Davis DANR. Publication 21567, 1998; 61-65.

14. Datta S, Sahgal PN, Subrahmaniyam S, Dhingra SC and VN Kishore Design and operating characteristics of evaporative cooling Systems. Rev. Int. Froid. 1987; 10: 205-208.

15. Seyoum TW and $\mathrm{K}$ Woldetsadik Forced ventilation evaporative cooling: A case study on banana, papaya, orange, mandarin, and lemon. Trop. Agric. 2004; 81 (3): 179-185.

16. Seyoum TW and $\mathrm{K}$ W oldetsadik Natural ventilation evaporative cooling of mango. J. Agric. Biotech. and Enviro. 2000; 2(1/2): 1-5.

17. Koca R, Hughes $\mathrm{W}$ and $\mathrm{L}$ Christiason Evaporative cooling pads test procedures and evaluation. App. Eng. Agric. 1994; 7(4): 485-490.

18. EL-Dessouky HT, Ettouney HM and W Bouhamra A novel air conditioning system membrane air drying and evaporative cooling. Trans. Institution of Chem. Eng. 2000; 78: 999-1009.

19. Seyoum TW The improvement of the shelf life of vegetables through pre and postharvest treatment. PhD dissertation, University of Free State. South Africa, 2002.

20. Lertsatitthanakorn C, Erngwongwitaya S and S Soponronnarit Field Experiments and Economic Evaluation of an Evaporative Cooling System in a Silkworm Rearing House. Biosys. Eng. 2006; 93(2): 213-219.

21. W att J R Evaporative Air Conditioning Handbook, 2nd Edn. Chapman Hall, London, UK, 1986.

22. Newnan DG Engineering Economic Analysis. Engineering Press Inc., California Sericulture Extension Center No. 1-9 and Sericulture Sub- Division (2002). Silk yarn quality development by farmer groups in Thailand. Proceedings of XIXth Congress of the International Sericultural Commission, pp 568-574, Bangkok, Thailand, 1980.

23. US Department of Commerce Ethiopia: Organic agriculture solutions. Trade Port: International Market Insight (IMI), 20.03.2000, (2000) http://www.state.gov/r/pa/ei/bgn/2859.htm. Accessed on 15/09/2008. 